\title{
ROBÔ-TI: Robótica Educacional no Incentivo de Alunos do Ensino Médio na Área de Tecnologia da Informação
}

\section{ROBÔ-TI: Educational Robotics in the Incentive of High School Students in the Area of Information Technology}

\author{
Joyce Miranda dos Santos \\ Instituto Federal de Educação, Ciência e Tecnologia do Amazonas \\ mds.joyce@gmail.com \\ Vitor Bremgartner da Frota \\ Instituto Federal de Educação, Ciência e Tecnologia do Amazonas \\ vitorbref@ifam.edu.br \\ Micila Medeiros Pereira \\ Instituto Federal de Educação, Ciência e Tecnologia do Amazonas \\ micila.pereira@ifam.edu.br \\ Hillermann Ferreira Osmidio Lima \\ Instituto Federal de Educação, Ciência e Tecnologia do Amazonas \\ hillermann@ifam.edu.br \\ José Pinheiro Queiroz Neto \\ Instituto Federal de Educação, Ciência e Tecnologia do Amazonas \\ josepqn@gmail.com
}

\section{Resumo}

Este artigo apresenta os resultados da realização de um projeto, chamado ROBÔ-TI, que foi desenvolvido com o objetivo de incentivar alunos de Ensino Médio da rede pública do Estado do Amazonas a ingressarem em carreiras na área de Tecnologia da Informação $(\mathrm{TI})$. Para isso, foram utilizadas práticas pedagógicas por meio da Aprendizagem Baseada em Problemas (ABP) visando o estímulo do Pensamento Computacional, com o uso de ferramentas como o Scratch e o Kit de Robótica Lego Mindstorms EV3. Os resultados obtidos, a partir de um questionário de Modelo de Aceitação de Tecnologia (TAM) e de depoimentos de alunos, demonstram a contribuição das estratégias de planejamento e de execução adotadas nesse projeto para a formação 


\title{
aEducitec \\ ISSN: 2446-774X
}

profissional e tecnológica de alunos e dos professores que receberam os treinamentos, estes últimos atuando como multiplicadores do conhecimento.

Palavras-chave: Robótica Pedagógica. Aprendizagem Baseada em Problemas. Tecnologia da Informação.

\begin{abstract}
This paper presents the results of a project, called ROBÔ-TI, that was developed with the objective of encouraging High School students from the public school system of the Brazilian State of Amazonas to enter careers in the area of Information Technology (IT). For this, pedagogical practices through ProblemBased Learning (PBL) aimed at the stimulation of Computational Thinking with the use of tools such as Scratch and Lego Mindstorms EV3 Robotics Kit. The results obtained from a Technology Acceptance Model (TAM) questionnaire and student testimonials, demonstrate the contribution of the planning and execution strategies adopted in this project for the professional and technological formation of students and teachers who received the training, the latter acting as multipliers of knowledge.
\end{abstract}

Key words: Pedagogical Robotics. Problem-Based Learning. Information Technology.

\section{Introdução}

O crescente avanço tecnológico tem feito surgir uma demanda cada vez maior por profissionais da área de Tecnologia da Informação (TI). Para suprir essa demanda, é de extrema importância o papel de formação de mão de obra especializada desempenhado por cursos de graduação nas áreas de engenharia e de tecnologia. Nesse sentido, tem existido uma preocupação em promover nos alunos da educação básica um interesse maior por carreiras nessas áreas, visando o atendimento das necessidades do mundo do trabalho.

Uma iniciativa que vem sendo adotada como alternativa para aumentar o engajamento por carreiras na área de TI é o trabalho com Robótica Pedagógica, também conhecida como Robótica Educacional (RE). A dinâmica do trabalho com a Robótica cria condições diversificadas de contextualização e de discussão, que conduzem o aluno a um maior envolvimento, tornando para ele a aprendizagem um processo mais atrativo e intuitivo. A Robótica Educacional ganha força por se tratar da aplicação da robótica na área pedagógica a fim de de disponibilizar aos alunos a oportunidade de criar soluções voltadas ao mundo real, de forma a possibilitar o aprendizado de forma dinâmica e mais estimulante (ALBUQUERQUE et al., 2016).

Uma das vantagens obtidas com a utilização da RE é o desenvolvimento do Pensamento Computacional (PC). Esse conceito aborda alguns fundamentos da Ciência da Computação com aplicações no dia-a-dia para a resolução de 


\section{alducitec \\ ISSN: 2446-774X}

problemas em diversas áreas do conhecimento, possibilitando uma interdisciplinaridade enquanto prática pedagógica. Diante disso, o estímulo do PC exerce uma importante relevância para a formação do aluno, pois permite a construção de habilidades, tais como: raciocínio lógico, pensamento crítico, tomadas de decisão, capacidade de reconhecimento de padrões e resolução de problemas (WING, 2006). Atualmente, a grande maioria dos alunos da educação básica não tem a oportunidade de ter contato com contextos que promovam ou estimulem o pensamento computacional (ZANETTI e OLIVEIRA, 2015).

Observada essa realidade, o projeto ROBÔ-TI foi proposto com o objetivo de incentivar alunos de Ensino Médio da rede pública do Estado do Amazonas a ingressarem em carreiras na área de $\mathrm{TI}$ e com isso, contribuir com a melhoria do processo de aprendizagem presente no cotidiano escolar desses alunos, por meio da utilização da Robótica Educacional e da Aprendizagem Baseada em Problemas (ABP ou PBL, do inglês, Problem-Based Learning), buscando assim propiciar um ambiente que estimule e aumente o interesse desses alunos na atuação em carreiras na área de TI. Sendo assim, a questão de pesquisa abordada neste artigo é se é possível incentivar (no sentido de estimular, motivar) alunos do Ensino Médio Básico na área de TI por meio da RE.

Este projeto foi promovido pelo Instituto Federal do Amazonas, Campus Manaus Distrito Industrial (IFAM CMDI). Os Institutos Federais em geral têm por finalidade realizar e estimular a pesquisa aplicada, a produção cultural, 0 empreendedorismo, o cooperativismo e o desenvolvimento científico e tecnológico. O desenvolvimento deste projeto teve o apoio do Centro de Tecnologia Professor Harlan Marcelice, situado no IFAM CMDI, que foi projetado com uma infraestrutura de laboratórios voltados para atividades com foco na investigação acadêmica aplicada, na divulgação científica e na geração de propriedade intelectual de forma a promover o desenvolvimento científico e tecnológico da região.

Para a realização deste projeto, foram contemplados oito municípios do Estado do Amazonas, sendo eles: Manaus, Presidente Figueiredo, Manacapuru, Maués, Itacoatiara, Parintins, Coari e Tefé. Todos esses municípios possuem um campus do IFAM atuante que se encontra equipado com infraestrutura e profissionais capacitados para oferecer 0 apoio necessário para 0 desenvolvimento deste projeto.

Como estratégia para a execução deste projeto nos municípios propostos, foram ministrados cursos de capacitação para professores do IFAM que efetivamente trabalham nesses municípios. Os servidores formados nos cursos de capacitação puderam promover nos municípios uma educação continuada, uma vez que foram capacitados como multiplicadores do conhecimento. Esses servidores puderam treinar os professores da rede estadual de ensino para que estes também tenham habilidades para estimular o Pensamento Computacional e incentivar o ingresso dos alunos em carreiras na área de $\mathrm{TI}$.

Dentre as ações para a execução deste projeto estiveram a utilização do software Scratch (SCRATCH, 2018) e kits Lego Mindstorms EV3 (EV3, 2018). O kit Lego Mindstorms EV3 é considerado um kit de referência em Robótica Educacional que se destaca tanto por sua característica lúdica como por permitir 


\section{Eteducitec \\ ISSN: 2446-774X}

construir diferentes tipos de robôs e ambientes automatizados para diferentes contextos. Esse kit apresenta significativa liberdade e flexibilidade para a montagem de estruturas mecânicas devido à grande quantidade de peças. Também se verifica na literatura sobre a temática da Robótica Educacional, muitos trabalhos que obtiveram resultados satisfatórios por meio da utilização do kit Lego, como Cambruzzi e Souza (2015) e Rios e Netto (2018).

Durante a execução deste projeto, foram organizados eventos na modalidade de competição. Neste projeto, a organização das competições seguiu o padrão da Olimpíada Brasileira de Robótica (OBR, 2018). A OBR é uma das olimpíadas científicas brasileiras cuja temática é a Robótica e tem o objetivo de estimular os jovens às carreiras científico-tecnológicas, identificar jovens talentosos e promover debates e atualizações no processo de ensino-aprendizagem brasileiro. A OBR destina-se a todos os estudantes de qualquer escola pública ou privada do ensino fundamental, médio ou técnico em todo o território nacional. Durante a OBR são definidas tarefas e as equipes devem construir robôs que atendam a estas tarefas. $\mathrm{Na}$ OBR, os robôs podem ser integralmente construídos pelos alunos ou podem ser construídos utilizando kits robóticos.

Durante a execução do projeto ROBÔ-TI, as competições foram desenvolvidas utilizando uma abordagem de torneio local (em cada município) e uma abordagem de torneio estadual. No torneio local, as equipes dos municípios competiram entre si, e no torneio estadual, todas as equipes dos municípios participaram de uma competição em Manaus. A inclusão dos alunos neste tipo de evento é uma estratégia para que estes se sintam ainda mais motivados a seguirem carreiras voltadas para a área de TI. No trabalho de Rüedell et al. (2018), é apresentado que pode haver aprendizado em estudantes que participam de competições locais de robótica.

O desenvolvimento deste projeto ofereceu aos alunos de escolas públicas do Estado do Amazonas 0 acesso a modernas tecnologias digitais, 0 desenvolvimento do Pensamento Computacional e a possibilidade de identificarem habilidades voltadas para áreas de TI que poderão efetivamente resultar no ingresso destes em carreiras de cunho científico e tecnológico.

A escolha da temática deste projeto se justificou pela crescente importância da Robótica na área educacional, principalmente no ensino médio, se configurando como uma das áreas de pesquisa em crescimento nesta década, e também devido à falta de incentivo para a formação de recursos humanos na área de Tecnologia da Informação. Com base nessa realidade, divulgar a Robótica e suas aplicações por meio deste projeto foi uma forma de estimular e promover o interesse de alunos do Ensino Médio por carreiras de cunho científicotecnológico, visando o atendimento das demandas atuais e futuras do mundo do trabalho.

Dentro desse contexto, o projeto ROBÔ-TI se insere com os seguintes objetivos específicos:

a) Qualificar professores dos municípios para aplicação de Robótica Educacional junto aos alunos da educação básica como forma de 


\section{areducitec \\ ISSN: 2446-774X}

promoção do interesse por carreiras na área de Tecnologia da Informação (TI);

b) Qualificar alunos do ensino médio para o desenvolvimento de aplicações em Robótica Educacional, com foco em programação;

c) Permitir aos alunos uma visão prática de conteúdos multidisciplinares por meio de construções e experimentos robóticos;

d) Estimular nos alunos o desenvolvimento do Pensamento Computacional para analisar e propor soluções para problemas apresentados.

\section{Fundamentação Teórica}

As novas tecnologias têm sido cada vez mais uma realidade presente na vida dos adolescentes brasileiros, mesmo nas pequenas cidades do interior do estado do Amazonas. Ainda que com dificuldades de acesso, a grande maioria possui um smartphone e utiliza redes sociais, aplicativos de pesquisa, jogos, entre outros. Por outro lado, incentivar estes alunos a um processo de ensino e aprendizagem moderno tem sido um grande desafio, pois ainda se utiliza muito nas escolas o padrão tradicional do ensino centrado no professor, expositivo, com o aluno numa posição passiva e recebedor de informações.

Entre as alternativas de metodologias ativas de ensino, a RE vem ganhando destaque no processo de ensino-aprendizagem, não apenas por sua habilidade de promover a interdisciplinaridade entre diferentes áreas do conhecimento, mas também por valorizar a coletividade e motivar a participação de alunos (BENITTI, 2012). Diversas Instituições de ensino pelo mundo inteiro têm utilizado em seu processo de ensino-aprendizagem a $R E$, que tem sido uma ferramenta tecnológica com um alto potencial motivador no âmbito da educação.

Basicamente, a RE tem como foco proporcionar ao aluno uma maneira prática e lúdica de investigação e materialização de conceitos previstos no conteúdo curricular. A aplicação da RE deve ir além de apenas montar e construir pequenos robôs e de desenvolver sua programação. De fato, a mesma proporciona um aprendizado hands-on que desenvolve o raciocínio lógico e a capacidade de analisar problemas e encontrar soluções aos desafios propostos.

Entretanto, a Robótica Educacional por si só não atinge seus objetivos se não estiver dentro de uma metodologia de aprendizagem mais consistente, como no caso deste trabalho, na qual utilizamos o método de Aprendizagem Baseada em Problemas (ABP). Quando aplicada junto à $A B P$, a RE incentiva o trabalho em equipe, a colaboração, o planejamento, a pesquisa, processos de tomada de decisões, assim como a interação entre os pares em um clima animado que permite administrar conflitos e respeitar ideias e opiniões diferentes, mas em busca de um resultado comum (EGUCHI, 2014).

A Aprendizagem Baseada em Problemas é um método que organiza a aprendizagem em torno de problemas a serem resolvidos, envolvendo os alunos em uma pesquisa construtiva na qual a investigação é um processo dirigido a um objetivo concreto que envolve pesquisa, construção do conhecimento e solução do desafio proposto. A ABP se desenvolve a partir do trabalho coletivo em uma perspectiva de autonomia e colaboração. A centralidade de todo o 


\section{Eteducitec \\ ISSN: $2446-774 X$}

processo está nos alunos e não no professor, que lidera e planeja as situações de aprendizagem, mas a ação em busca do conhecimento é realizada exclusivamente pelos estudantes.

Nessa perspectiva, todo trabalho deve ser iniciado por um problema a ser resolvido ou um desafio a ser vencido pelos alunos, sendo este último mais comum na RE. Os alunos possuem autonomia na escolha da solução do problema que seu grupo irá lidar e nos métodos para desenvolver essa solução. Geralmente, os trabalhos desenvolvidos culminam na elaboração de algum protótipo ou processo representativo da solução encontrada para o problema ou desafio. Particularmente na RE, o trabalho culmina com a construção e programação do robô para alcançar e/ou superar determinada tarefa.

Portanto, atuar junto aos docentes que participaram deste projeto para que os mesmos tivessem uma formação nos conceitos pedagógicos e técnicos da RE, aliada aos procedimentos da ABP, foi não apenas uma ação necessária, mas fundamental para o sucesso deste trabalho.

\section{Métodos Utilizados}

Inicialmente, foi realizada a etapa de planejamento, na qual estiveram contempladas as seguintes atividades: aquisição de materiais, seleção de bolsistas, confecção de material didático, capacitação de professores multiplicadores e a capacitação de alunos.

A partir da liberação dos recursos financeiros definidos na proposta do projeto, foram adquiridos os materiais necessários, que eram os kits Lego EV3 para o desenvolvimento e execução do projeto. Com relação à seleção dos bolsistas, primeiro foram selecionados os professores que atuariam como multiplicadores junto às escolas dos municípios. Os professores selecionados atuaram diretamente na seleção dos alunos bolsistas das turmas dos seus respectivos municípios.

\section{Fase de Capacitação dos Professores}

Durante a fase de planejamento, a equipe técnica do projeto foi responsável por confeccionar o material didático a ser usado pelos professores bolsistas em sala de aula. Este planejamento considerou a infraestrutura e organização adotadas pela Olimpíada Brasileira de Robótica (OBR) de forma a adequá-las à realidade do projeto. A equipe técnica também ficou responsável por preparar um curso de capacitação de curta duração que foi ministrado para os professores dos municípios antes do início da atuação em sala de aula junto aos alunos.

A capacitação foi realizada com o objetivo de tornar os professores dos municípios multiplicadores da aplicação da Robótica Educacional com o uso do Kit Lego EV3. Dessa forma, os professores aqui podem também ser chamados de multiplicadores.

Com uma duração de 3 dias, aconteceu o Curso de Capacitação de Multiplicadores, no qual estiveram presentes representantes dos 8 municípios contemplados pelo Projeto ROBÔ-TI. O conteúdo do curso foi organizado de 


\section{Eteducitec \\ ISSN: $2446-774 X$}

forma a permitir que os professores dos municípios se tornassem multiplicadores da aplicação da RE em sala de aula com o uso do Kit Lego EV3 Mindstorms.

No primeiro dia, a equipe técnica atuou para demonstrar o que é a Robótica Educacional e como ela pode ser aplicada em sala de aula com os alunos visando o estímulo ao Pensamento Computacional de forma lúdica. Cada participante recebeu um Kit Lego para ser utilizado durante o curso. Nesse momento, foi dada a missão para que cada professor montasse o seu próprio robô educador. Foram apresentadas as competições de robótica (OBR e First Lego League - FLL) (OBR, 2018; FLL, 2018). Depois, foi iniciada a utilização do Brick, componente do EV3, e do software EV3, para fazer a primeira atividade, que era programar o movimento do robô em linha reta.

No segundo dia, o conteúdo foi direcionado para o estudo de diferentes sensores (de cor, de toque e ultrassônico), possíveis de serem acoplados ao robô. Dessa forma, foi possível desenvolver tarefas com o objetivo de simular os desafios propostos nas competições de robótica que reúnem vários estudantes todo ano, seja em nível regional, nacional ou internacional. Esses desafios consistiam em programar os robôs para realizarem curvas e seguirem bordas e linhas, conforme apresentado na Figura 1.

No terceiro e último dia de capacitação foi o ápice do evento, no qual foi realizado o Minitorneio de Robótica. Os professores foram divi didos em duplas e então puderam vivenciar toda a tensão e emoção vividas durante as competições de robótica. Nesse momento, foram repassadas para os professores as principais regras seg uidas nesse tipo de competição. Após o Mini Torneio de Robótica entre professores do Projeto ROBÔ-TI, ocorreu uma premiação simbólica para as duplas que ficaram nos três primeiros lugares.

Figura 1 - Professores testando seus robôs seguidores de linha.

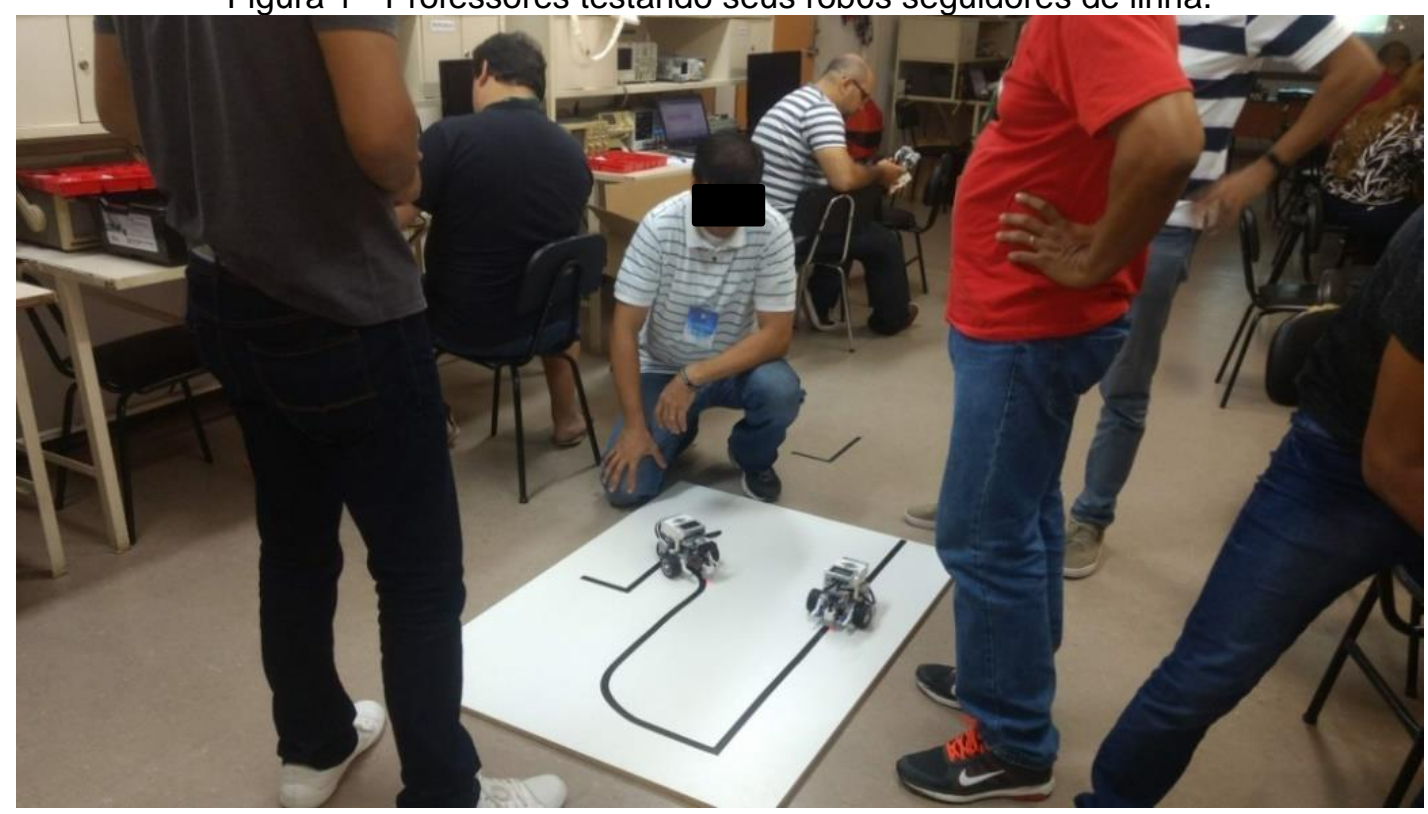

Fonte: Próprios autores (2018). 


\section{aEducitec \\ ISSN: 2446-774X}

\section{Fase de Capacitação dos Alunos}

Após a conclusão da capacitação dos professores bolsistas, foi iniciada a etapa de capacitação dos alunos. Foram formadas turmas de 20 alunos em cada um dos 8 municípios, com exceção de Manaus, que contemplou 30 alunos. As aulas foram realizadas três vezes na semana com duração de três horas cada aula. As aulas tinham que ser promovidas de forma a contemplar metodologias e didática diferenciadas do modelo convencional já ofertado pelo sistema de ensino regular, com enfoque principal em atividades práticas e na Aprendizagem Baseada em Problemas, a fim de estimular o Pensamento Computacional nos estudantes.

O treinamento com os alunos foi dividido em 3 módulos:

a) Módulo 1 - Introdução à Tecnologia da Informação (12 horas), que tinha como objetivo apresentar conceitos relacionados à tecnologia da informação e demonstrar aplicações práticas do uso da tecnologia, de forma a evidenciar necessidades do mundo real e suas soluções. Sua ementa foi composta da seguinte forma: Conceituação e aplicações da Tecnologia da Informação (TI); Fundamentos de Sistemas Computacionais; Tecnologias Emergentes.

b) Módulo 2 - Lógica de Programação (30 horas), que tinha como objetivo desenvolver o raciocínio lógico e utilizar técnicas de programação na construção de algoritmos, consolidando o aprendizado através de aplicações com programação em blocos. Sua ementa foi composta da seguinte forma: Conceituação de Lógica; Princípios de Lógica de Programação; Construção de Algoritmos; Fluxograma; Pseudocódigo; Programação em Blocos. Importante ressaltar que aqui foi utilizado o Scratch para a programação em blocos.

c) Módulo 3 - Programação Aplicada à Robótica (68 horas), que tinha como objetivo consolidar o aprendizado de lógica de programação por meio da programação das estruturas robóticas montadas com os kits Lego, preparando os alunos para atuarem em competições de robótica em geral. Sua ementa era: Conceito de robótica e aplicações com Lego EV3; Construção de um robô com EV3; O Brick EV3 e o software EV3 Mindstorms; Movimentando o robô; Inserindo sensores no Robô; Seguidor de borda e linha; Competição entre alunos da mesma turma. A Figura 2 mostra alunos aprendendo a manipular os kits Lego EV3. 
ISSN: $2446-774 X$

Figura 2 - Alunos da rede estadual aprendendo a manipular os kits Lego EV3. À esquerda, no município de Itacoatiara, estudantes programando em blocos um robô LEGO. À direita, em

Coari, estudantes montam seu robô.

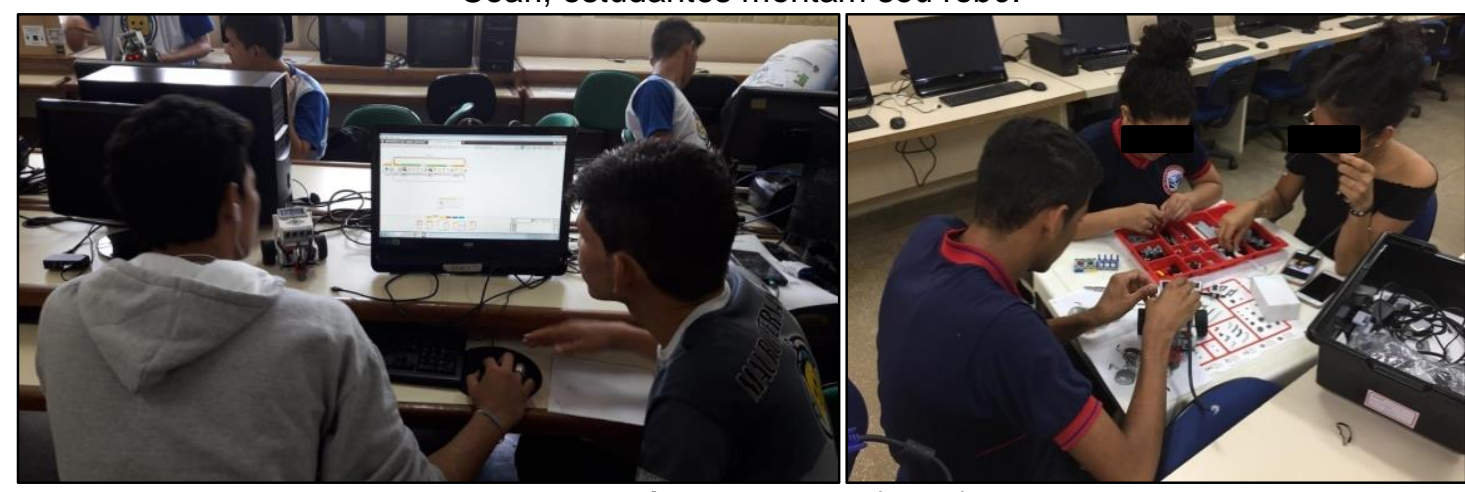

Fonte: Próprios autores (2018).

Os alunos foram estimulados a trabalharem em equipe e a participarem das competições. Foi realizada uma competição local, na qual as equipes de cada município competiram entre si e uma competição estadual (o torneio final de Robótica, explicado a seguir), na qual todas as equipes dos municípios competiram em um evento realizado em Manaus no IFAM CMDI.

\section{O Torneio Final de Robótica}

O Torneio Final de Robótica teve a participação de 16 equipes, sendo 2 de cada um dos 8 municípios que participam do projeto ROBÔ-TI e que obtiveram o melhor desempenho no torneio em sua cidade local.

O torneio marcou o fechamento do projeto ROBÔ -TI e seu objetivo foi mostrar o resultado da capacitação realizada com os alunos, através do cumprimento de diversos desafios com os robôs programados. A Figura 3 mostra as equipes se preparando para as provas do torneio final. O torneio foi realizado em três fases, sendo a primeira referente à Modalidade Seguidor de Linha, a segunda referente à Modalidade de Labirinto de Cores e a terceira, um desafio surpresa, onde participaram apenas as 6 equipes que somaram a maior pontuação na primeira e segunda fases.

Figura 3 - Equipes de diferentes municípios se preparando para as fases do Torneio Final.

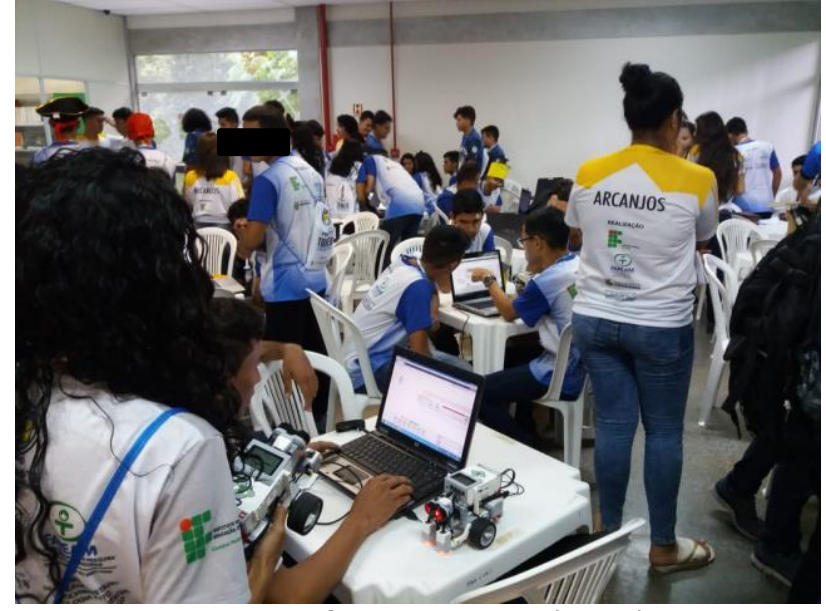

Fonte: Próprios autores (2018). 


\section{Eteducitec \\ ISSN: 2446-774X}

O primeiro desafio consistiu em um cenário onde o Robô deveria percorrer um piso branco de MDF com um percurso em linha preta de $2 \mathrm{~cm}$ de largura, feito com fita isolante comum de $19 \mathrm{~mm}$. A linha poderia ter gaps (interrupções na linha preta), curvas, obstáculos e cruzamentos, os quais o robô deveria superar todos esses percalços para continuar o trajeto. Foi tarefa de cada robô lidar da melhor forma possível com os problemas do piso que simulam o mundo real. A Figura 4 mostra um cenário utilizado nesta fase. Ao desviar de um obstáculo, o robô deveria retornar para a linha logo após o obstáculo desviado para obter sucesso. Não era permitido ao robô seguir por outra linha da arena nem a mesma linha, caso ele já tenha mudado de direção após o obstáculo. Se o robô não conseguisse retornar à linha, seria considerada falha de progresso, forçando o robô a reiniciar o seu percurso.

Figura 4 - Arena da primeira fase no Torneio Final: Robô Seguidor de Linha.

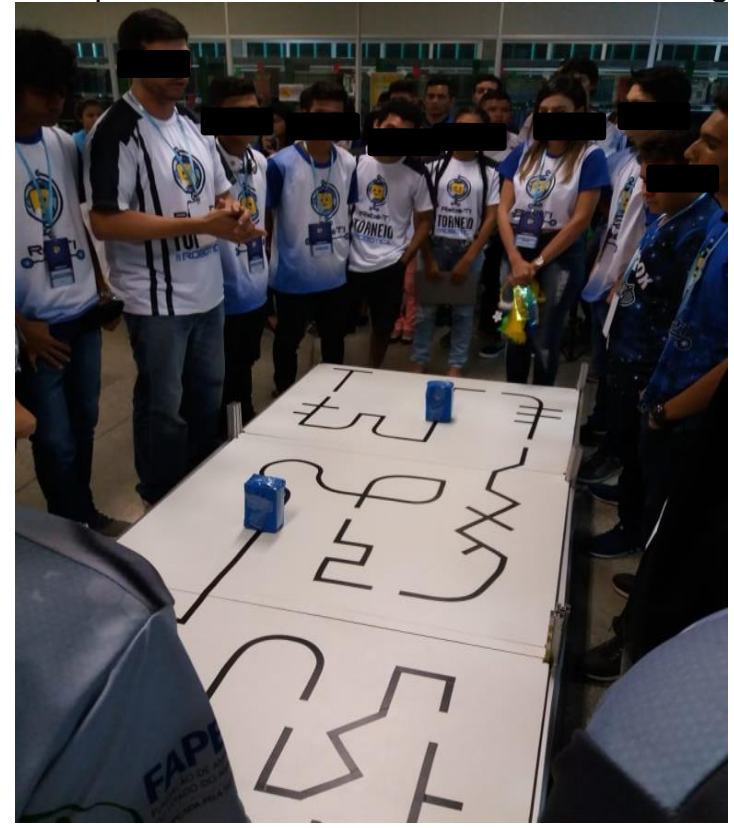

Fonte: Próprios autores (2018).

Todas as equipes poderiam treinar antes de serem chamadas para a rodada oficial. O treino poderia ser feito na arena oficial ou poderia ser disponibilizada uma arena alternativa, com todos os itens que estariam presentes na arena oficial. Na fase do Labirinto de Cores, o Robô deveria percorrer uma trajetória orientada por cores, como ilustrado na Figura 5. 


\section{Ededucitec \\ ISSN: 2446-774X}

Figura 5 - Arena da segunda fase no Torneio Final: Labirinto de Cores.

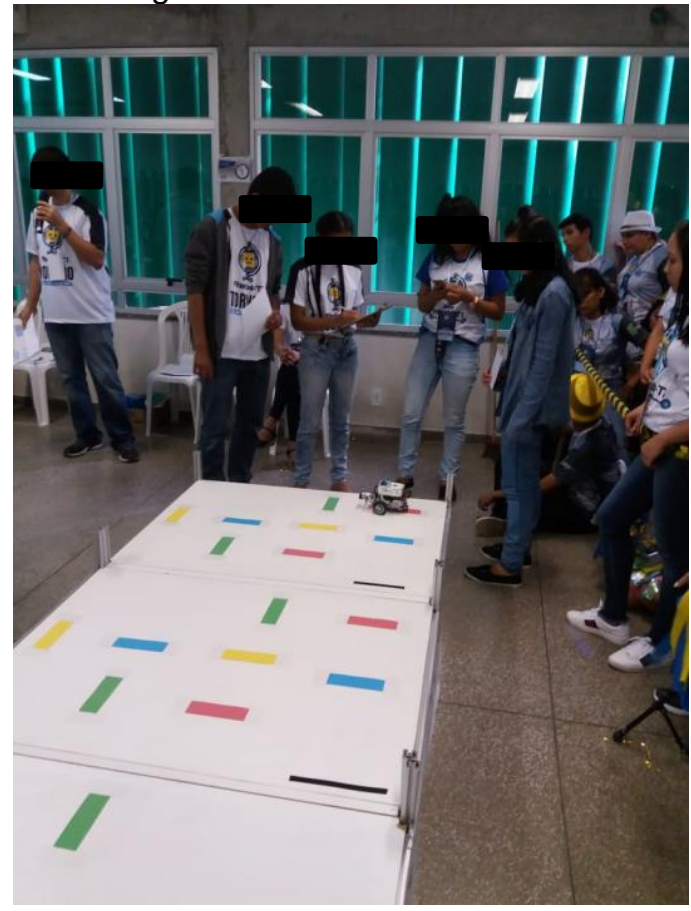

Fonte: Próprios autores (2018).

$\mathrm{Na}$ arena estava presente um total de quatro cores (verde, amarela, vermelha e azul), onde cada uma possuía uma pontuação que foi apresentada pela organização no momento da prova e dependia de sua posição na arena.

Para realizar com sucesso o labirinto de cores, o robô deveria:

- Identificar a cor;

- Girar para o lado adequado;

- Obrigatório parar por 1 segundo ou emitir um som;

- Localizar a próxima cor;

- Repetir o processo até a última cor, onde deveria desligar os motores.

A equipe teria apenas uma largada, onde deveria posicionar o Robô na linha de largada. Por fim, as seis equipes que obtiveram a maior soma nas fases 1 e 2 foram classificadas para a terceira e última fase do torneio. A fase final se constituiu em um desafio surpresa apresentado pela organização, onde as equipes tinham um tempo limitado para elaborar o programa para solução do desafio. O desafio surpresa consistia em uma corrida de estouro de balão, onde cada equipe tinha 1 minuto para estourar 3 balões na arena. Ganharia quem estourasse o maior número de balões em menor tempo. A Figura 6 mostra o momento da reunião das equipes com os juízes antes do desafio final. 


\section{Eteducitec \\ ISSN: $2446-774 X$}

Figura 6 - Arena da última fase no Torneio Final: Desafio Surpresa de Estouro de balões.

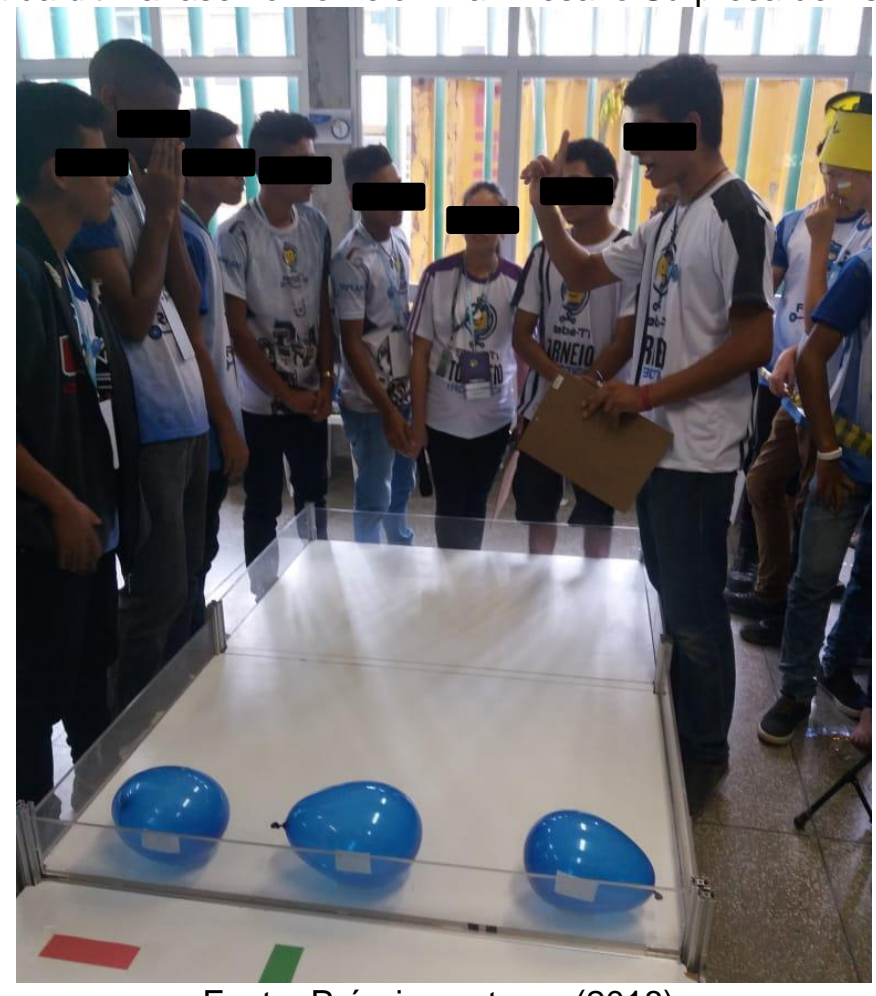

Fonte: Próprios autores (2018).

\section{Resultados Obtidos}

Durante a capacitação dos alunos, ao final dos Módulos 2 e 3, foram aplicados questionários para os alunos de Ensino Médio ( $1^{\circ}$ ao $3^{\circ}$ ano) dos 8 municípios, tanto a respeito de suas experiências com o Scratch (em que 127 alunos responderam) quanto com o Lego EV3 (em que 136 alunos responderam). Por questões éticas, os alunos preencheram e assinaram um Termo de Consentimento Livre e Esclarecido (TCLE) antes de responderem os questionários. As percepções dos alunos foram coletadas através do questionário pós-aplicação, que foi baseado no Modelo de Aceitação de Tecnologia (TAM) (DAVIS, 1989). Os dados qualitativos foram coletados em relação a fatores determinantes de aceitação da ferramenta tecnológica, a partir de sua facilidade de uso e utilidade. A Tabela 1 apresenta os resultados do questionário no modelo TAM aplicado aos alunos a respeito do uso do Scratch, durante o Módulo 2. 
ISSN: $2446-774 X$

Tabela 1 - Respostas dos alunos ao questionário TAM com respeito ao Scratch. Considerando a sua percepção sobre a facilidade do uso do Scratch, qual o seu grau de concordância em relação às seguintes perguntas:

\begin{tabular}{lcccc}
\hline Pergunta & $\begin{array}{c}\text { Concordo } \\
\text { Amplament } \\
\text { e }\end{array}$ & $\begin{array}{c}\text { Concordo } \\
\text { Parcialmente }\end{array}$ & $\begin{array}{c}\text { Discordo } \\
\text { Parcialmente }\end{array}$ & $\begin{array}{c}\text { Discordo } \\
\text { Totalmente }\end{array}$ \\
\hline $\begin{array}{l}\text { Foi fácil aprender a utilizar o } \\
\text { SCRATCH? }\end{array}$ & $49,6 \%$ & $46,5 \%$ & $3,9 \%$ & $0 \%$ \\
$\begin{array}{l}\text { Você sentiu algum tipo de } \\
\text { dificuldade ao utilizar 0 }\end{array}$ & $7,9 \%$ & $42,5 \%$ & $26,8 \%$ & $22,8 \%$ \\
$\begin{array}{l}\text { SCRATCH? } \\
\text { É fácil lembrar como utilizar }\end{array}$ & $46,5 \%$ & $43,3 \%$ & $10,2 \%$ & $0 \%$ \\
$\begin{array}{l}\text { O SCRATCH para } \\
\text { aplicações futuras? }\end{array}$ & & & & \\
$\begin{array}{l}\text { Foi fácil aplicar os conceitos } \\
\text { de Lógica de Programação } \\
\text { vistos em sala de aula com }\end{array}$ & $52,8 \%$ & $40,9 \%$ & $6,3 \%$ & $0 \%$ \\
o uso do SCRATCH? & & & & \\
\hline
\end{tabular}

Considerando a sua percepção sobre a utilidade do Scratch, qual o seu grau de concordância em relação às seguintes perguntas:

\begin{tabular}{lcccc}
\hline Pergunta & $\begin{array}{c}\text { Concordo } \\
\text { Amplament } \\
\text { e }\end{array}$ & $\begin{array}{c}\text { Concordo } \\
\text { Parcialmente }\end{array}$ & $\begin{array}{c}\text { Discordo } \\
\text { Parcialmente }\end{array}$ & $\begin{array}{c}\text { Discordo } \\
\text { Totalmente }\end{array}$ \\
\hline $\begin{array}{l}\text { O uso do SCRATCH } \\
\text { permitiu que você fixasse } \\
\text { de forma satisfatória os }\end{array}$ & $61,4 \%$ & $34,6 \%$ & $3,9 \%$ & $0 \%$ \\
$\begin{array}{l}\text { conceitos de lógica de } \\
\text { programação vistos em sala } \\
\text { de aula? }\end{array}$ & & & & \\
$\begin{array}{l}\text { Usar o SCRATCH foi útil } \\
\text { para estimular seu interesse } \\
\text { pela área de Tecnologia da }\end{array}$ & $71,7 \%$ & $22 \%$ & $5,5 \%$ & $0,8 \%$ \\
$\begin{array}{l}\text { Informação (TI)? } \\
\text { O desenvolvimento de }\end{array}$ & $76,4 \%$ & $19,7 \%$ & $3,1 \%$ & \\
jogos usando o SCRATCH \\
motivou você a querer \\
$\begin{array}{l}\text { aprender mais a respeito } \\
\text { sobre a área de Tecnologia } \\
\text { da Informação (TI)? }\end{array}$
\end{tabular}

Podemos perceber, com os dados da Tabela 1, que a maioria dos alunos aceitaram a forma como foi constituído o processo de ensino-aprendizagem de Lógica de Programação por meio do Scratch. Os índices positivos a respeito da utilidade foram mais expressivos que os da facilidade de uso do Scratch. Percebe-se que para estes alunos, a lógica de programação é uma novidade e há de destacar que os alunos obtiveram grande interesse no desenvolvimento 


\section{Ededucitec \\ ISSN: $2446-774 X$}

de jogos utilizando o Scratch, que foi uma importante ferramenta para o conteúdo que estaria por vir, o uso do Lego EV3.

Também foram feitas algumas perguntas dissertativas para os alunos exporem suas opiniões e algumas foram escolhidas para serem transcritas literalmente como eles escreveram.

Na pergunta: O que você aprendeu com o uso do SCRATCH? Algumas respostas de destaque foram: Programar Scratch é facil, os comandos que dizem ao computador o que ele tem que fazer. Esses comandos são figuras que você pode arrastar e juntar para fazer os seus programas dependo do projeto pedido pelo professor. Também é um ótimo programador de jogos com gráficos semelhantes ao do mario (sic) e outros; APRENDI A DESENVOLVER $O$ RACIOCÍNIO LÓGICO E A PROGRAMAR TAMBÉM; muitas coisas que até mesmo eu não sabia, inclusive saber que a área de ti (sic) é muito mais complexa e desenvolvida, e gostei muito de aprender várias coisas novas e o scratch me ajudou a perceber que tudo na vida tem uma lógica, além do mais o scratch foi uma coisa nova e fez com que eu gostasse ainda mais da área de informática e no futuro quero ingressar nessa área.

Na pergunta: Quais foram suas maiores dificuldades ao usar o SCRATCH? Algumas respostas de destaque foram: Nenhuma; Utilizar os blocos de programação; FORAM OS BLOCOS; No começo a maior dificuldade foi na organização dos blocos e suas funções, mas no decorrer do projeto passei a dominar essas funções com maior facilidade". Percebe-se que incialmente, a maior dificuldade dos alunos foram a manipular os blocos, visto que tanto a lógica de programação quanto o Scratch eram uma novidade para os alunos.

Na pergunta: Use o espaço a seguir para fazer comentários gerais que julgar necessários sobre a experiência vivida com o uso do SCRATCH, destacamos as seguintes respostas: FOI UMA EXPERIÊNCIA NOVA, CHAMOU MAIS ATENÇÃO NA FORMA DE MONTAR OS BLOCOS; O Scratch foi algo muito bom, que levou cada aluno ter novos conhecimentos e a gostar da parte da tecnologia, no começo teve dificuldades, mais depois que superamos as dificuldades e aprendemos a utilizar, as coisas se saíram bem; O SCRATCH possui diversas formas de uso, tanto para jogos de diversas modalidades, hitórias (sic) educativas, etc... Ele nos propõe a liberdade da criatividade; $O$ SCRATCH me proporcionou uma base satisfatória e necessária para iniciar o estudo de programação. Sua aplicação lúdica e facilidade foi o que mais contribuiu para o meu aprendizado, e posteriormente, também favoreceu 0 desenvolvimento da programação na robótica. Percebemos que os depoimentos dos alunos mostram que eles gostaram de usar o Scratch.

A Tabela 2 a seguir apresenta os resultados dos questionários no modelo TAM aplicado aos alunos com respeito ao uso do kit Lego EV3. São as mesmas perguntas, exceto a penúltima pergunta com respeito à utilidade, devido às diferenças que existem entre utilizar o Scratch e o EV3. 


\section{Ededucitec

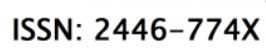

Tabela 2 - Respostas dos alunos ao questionário TAM com respeito ao EV3.

Considerando a sua percepção sobre a facilidade do uso do kit LEGO EV3, qual o seu grau de concordância em relação às seguintes perguntas:

\begin{tabular}{|c|c|c|c|c|}
\hline Pergunta & $\begin{array}{c}\text { Concordo } \\
\text { Amplament } \\
\text { e }\end{array}$ & $\begin{array}{l}\text { Concordo } \\
\text { Parcialmente }\end{array}$ & $\begin{array}{l}\text { Discordo } \\
\text { Parcialmente }\end{array}$ & $\begin{array}{l}\text { Discordo } \\
\text { Totalmente }\end{array}$ \\
\hline $\begin{array}{l}\text { Foi fácil aprender a utilizar o } \\
\text { kit LEGO EV3? }\end{array}$ & $65,4 \%$ & $30,9 \%$ & $2,9 \%$ & $0,7 \%$ \\
\hline $\begin{array}{l}\text { Você sentiu algum tipo de } \\
\text { dificuldade ao utilizar o kit } \\
\text { LEGO EV3? }\end{array}$ & $11 \%$ & $41,9 \%$ & $17,6 \%$ & $29,4 \%$ \\
\hline $\begin{array}{l}\text { É fácil lembrar como utilizar } \\
\text { o kit LEGO EV3 para } \\
\text { aplicações futuras? }\end{array}$ & $51,5 \%$ & $38,2 \%$ & $8,8 \%$ & $1,5 \%$ \\
\hline $\begin{array}{l}\text { Foi fácil aplicar os conceitos } \\
\text { de Lógica de Programação } \\
\text { vistos em sala de aula com } \\
\text { o uso do kit LEGO EV3? }\end{array}$ & $50,7 \%$ & $44,9 \%$ & $3,7 \%$ & $0,7 \%$ \\
\hline \multicolumn{5}{|c|}{$\begin{array}{l}\text { Considerando a sua percepção sobre a utilidade do kit LEGO EV3, qual o seu grau de } \\
\text { concordância em relação às seguintes perguntas: }\end{array}$} \\
\hline Pergunta & $\begin{array}{c}\text { Concordo } \\
\text { Amplament } \\
\text { e }\end{array}$ & $\begin{array}{l}\text { Concordo } \\
\text { Parcialmente }\end{array}$ & $\begin{array}{l}\text { Discordo } \\
\text { Parcialmente }\end{array}$ & $\begin{array}{l}\text { Discordo } \\
\text { Totalmente }\end{array}$ \\
\hline $\begin{array}{l}\text { O uso do kit LEGO EV3 } \\
\text { permitiu que você fixasse } \\
\text { de forma satisfatória os } \\
\text { conceitos de lógica de } \\
\text { programação vistos em sala } \\
\text { de aula? }\end{array}$ & $65,4 \%$ & $27,2 \%$ & $5,9 \%$ & $1,5 \%$ \\
\hline $\begin{array}{l}\text { Usar o kit LEGO EV3 foi útil } \\
\text { para estimular seu interesse } \\
\text { pela área de Tecnologia da } \\
\text { Informação }(\mathrm{TI}) ?\end{array}$ & $76,5 \%$ & $20,6 \%$ & $2,9 \%$ & $0 \%$ \\
\hline $\begin{array}{l}\text { A construção e } \\
\text { programação de robôs } \\
\text { usando o kit LEGO EV3 } \\
\text { motivou você a querer } \\
\text { aprender mais a respeito } \\
\text { sobre a área de Tecnologia } \\
\text { da Informação }(\mathrm{TI}) ?\end{array}$ & $77,9 \%$ & $21,3 \%$ & $0,7 \%$ & $0 \%$ \\
\hline $\begin{array}{l}\text { As atividades desenvolvidas } \\
\text { com o kit LEGO EV3 } \\
\text { aumentaram seu interesse } \\
\text { em seguir carreira na área } \\
\text { de Tecnologia da } \\
\text { Informação? }\end{array}$ & $68,4 \%$ & $28,7 \%$ & $2,9 \%$ & $0 \%$ \\
\hline
\end{tabular}

Podemos perceber, pelos índices mostrados na Tabela 2, que a aceitação dos alunos com relação ao kit Lego EV3 é ainda maior do que o uso do programa Scratch, principalmente quando comparamos os índices de utilidade do uso de ambas as ferramentas.

Assim como ocorreu com relação ao uso do Scratch, após o uso do Lego EV3 também fizemos algumas perguntas dissertativas para os alunos exporem suas opiniões que foram transcritas literalmente como eles escreveram. 


\section{aEducitec \\ ISSN: 2446-774X}

Na pergunta: O que você aprendeu com o uso do kit Lego EV3? Algumas respostas de destaque foram: Programação; Lógica de Programação; A montar, desmontar, criar varios tipos de robôs; $A$ usar a logica para fazer determinados tarefas simples que encontramos no nosso dia a dia. Varias formas de ter raciocinio logicos para determinadas acoes. $E$ a usar mais a matematica em tarefas diarias e que ficar mais dinamico. Percebemos que é quase unânime que os alunos disseram que o que eles mais aprenderam foi a programação.

Na pergunta: Quais foram suas maiores dificuldades ao usar o kit Lego EV3? Algumas respostas de destaque foram: Na hora da montagem; A montar um robô; Nos conhecimentos das peças; Algumas programações. Percebe-se que a maior dificuldade dos alunos com relação ao EV3 foi a respeito da montagem do robô.

Na pergunta: Use o espaço a seguir para fazer comentários gerais que julgar necessários sobre a experiência vivida com o uso do kit Lego EV3, destacamos as seguintes respostas: É ótimo ver que oque vc faz dentro do programa trás resultado no robô; Poderia ser mais barato; Indico a todos; Gostei muito do kit lego ev3 achei muito bom; É uma experiência que vou levar para a vida!; Ao decorrer das aulas, aprendemos coisas que nunca pensavamos que iriam ser precisas. O EV3 foi um dos equipamentos que mais nos propocionou conhecimento. Presenciei coisas que jamais tinha visto ao longo do tempo e aprendi bastante coisas. Isso foi muito interessante! Dessa forma, vimos que muitos alunos gostaram das experiências vividas e até gostariam de ter um kit Lego. Porém, consideraram caro tal kit, um fator do qual eles criticaram.

Com estes resultados obtidos, tanto pelos depoimentos dos alunos quanto pelos dados quantitativos nas Tabelas 1 e 2, que o projeto ROBÔ-TI contribuiu para o estímulo e a motivação dos alunos de Ensino Médio Básico a seguirem carreiras na área de TI, respondendo a questão de pesquisa apresentada na Introdução deste artigo.

\section{Conclusão}

O projeto ROBÔ-TI visou estimular o Pensamento Computacional dos estudantes de Ensino Médio das escolas da rede estadual de ensino no Estado do Amazonas, inserindo-os na área de Tecnologia da Informação por meio da Robótica Educacional e da Aprendizagem Baseada em Problemas. As ferramentas utilizadas, Scratch e Lego EV3, e as competições realizadas motivaram os alunos a buscarem mais conhecimentos relacionados à lógica de programação. Os resultados obtidos, tanto pelo questionário TAM aplicado quanto pelos depoimentos dos alunos, demonstram que o projeto teve altos índices de aceitação pelos alunos.

Além disso, foi possível alcançar os objetivos geral e específicos descritos na Introdução deste artigo. Um deles foi a formação de professores capacitados nos municípios para a aplicação e a multiplicação da prática de Robótica Educacional em sala de aula, permitindo uma mudança de paradigma no processo de ensinoaprendizagem de lógica de programação. Outro objetivo alcançado foi a 


\section{Eteducitec \\ ISSN: $2446-774 X$}

capacitação de alunos quanto à aplicação do Pensamento Computacional, utilizando a robótica para a solução de problemas que simulam o mundo real; houve o aumento do interesse dos alunos envolvidos por carreiras na área de Tecnologia da Informação ( $\mathrm{TI}$ ); além disso, foi estimulada a pesquisa e a formação de recursos humanos no interior do estado do Amazonas, dando maior capilaridade aos recursos disponíveis e descentralizando as ações que antes ocorriam apenas na capital Manaus.

Como trabalhos futuros, espera-se trabalhar em mais escolas públicas da capital e do interior do Estado do Amazonas, não somente estaduais, mas incluir as redes municipal e federal de ensino. Com isso, se propõe o aumento a médio e longo prazo da quantidade de profissionais capacitados para fornecer a mão-deobra especializada necessária ao mundo do trabalho nos setores voltados para a aplicação do conhecimento profissional e tecnológico.

\section{Agradecimentos}

Este artigo é fruto do projeto intitulado ROBÔ-TI: ROBÓTICA EDUCACIONAL NO INCENTIVO DE ALUNOS DO ENSINO MÉDIO PARA ATUAÇÃO NA ÁREA DE TECNOLOGIA DA INFORMAÇÃO, financiado pela Fundação de Amparo à Pesquisa do Estado do Amazonas (FAPEAM), contemplado no Edital $\mathrm{N}$. 010/2017 - RH-TI.

\section{Referências}

ALBUQUERQUE, D. et al. Uma Experiência do Uso Do Hardware Livre Arduino no Ensino De Programação De Computadores. In: V Congresso Brasileiro de Informática na Educação (CBIE 2016). Anais do XXII Workshop de Informática na Escola (WIE 2016), Uberlãndia, MG, 2016.

BENITTI, F.B.V. Exploring the educational potential of robotics in schools: a systematic review. Computers and Education, 58(3), pp. 978-988, 2012.

CAMBRUZZI, E.; SOUZA, R. M.; Robótica Educativa na aprendizagem de Lógica de Programação: Aplicação e análise. In: IV Congresso Brasileiro de Informática na Educação (CBIE 2015). Anais do XXI Workshop de Informática na Escola (WIE). Maceio, AL, 2015.

DAVIS, F. Perceived usefulness, perceived ease of use, and user acceptance of information technology. MIS Quarterly, p. 319-340, 1989.

EGUCHI, A. Robotics as a learning tool for educational transformation. In: International Workshop Teaching Robotics, Teaching with Robotics \& International Conference Robotics in Education, pp. 27-34, 2014.

EV3. Mindstorms Lego. Disponível em <https://www.lego.com/enus/mindstorms/about-ev3> Acesso em 26 de dez. de 2018.

FLL. FIRST LEGO League. Disponível em: <http://www.firstlegoleague.org/> Acesso em 26 de dez. de 2018. 


\section{eteducitec}

ISSN: 2446-774X

OBR. Olimpíada Brasileira de Robótica. Disponível em: $<$ http://www.obr.org.br/> Acesso em 26 de dez. de 2018.

RIOS, M; NETTO, J. F. M. MonitoRE: Um Arcabouço de Sistema para Monitoramento de Tarefas na Robótica Educacional. In: VII Congresso Brasileiro de Informática na Educação (CBIE 2018). Anais do XXIX Simpósio Brasileiro de Informática na Educação (SBIE 2018), Fortaleza, CE, 2018.

RÜEDELL, A.; TRENTIN, M. A.; FONTANA, A. Uma análise sobre 0 desempenho das equipes na 1a etapa de uma Olimpíada de Robótica Educativa Livre. Revista De Estudos E Pesquisas Sobre Ensino Tecnológico (EDUCITEC), 4(09). <https://doi.org/10.31417/educitec.v4i09.312>, 2018.

SCRATCH. Scratch - Imagine, Program, Share. Disponível em $<$ https://scratch.mit.edu/> Acesso em 26 de dez. de 2018.

WING, J. Computational Thinking. Communications of the ACM, 3 ed.: pp. 3335, 2006.

ZANETTI, H. A. P.; OLIVEIRA, C. L. V. Prática de ensino de Programação de Computadores com Robótica Pedagógica e aplicação de Pensamento Computacional. In: IV Congresso Brasileiro de Informática na Educação (CBIE 2015). Anais dos Workshops do IV Congresso Brasileiro de Informática na Educação (CBIE 2015), Maceió, AL, 2015.

Submetido em 27/12/2018.

Aceito em 08/05/2019. 